\title{
Postscript to the second edition: philosophy in and of public administration today, global-Western and non-Western Wolfgang Drechsler
}

I had concluded the first version of these reflections, the postscript to the first edition, by stating that Edoardo Ongaro's book on Philosophy and Public Administration (PA) came at a crucial time, and that it filled the gap of a missing book - modestly yet assuredly, with style and competence. It addresses, indeed, one of the most crucial issues of PA today, and that is the one of bringing the philosophical discourse into the picture - and well into the centre of it. I hoped that the research agenda it proposes, the filling-in of the lacunae in the matrices displayed in the first chapter, would be accomplished by PA scholars soon enough, and that it would enable and encourage the establishment of courses in, or at least covering, the subject of Philosophy and PA. Our discipline, but more crucially our administered world, as I said, would be better for it, both in equity and in performance.

And while some of these changes may still be in progress, the facts that, so soon after the first, there will be this second edition; that a very impressive set of translations is in the works; and that the reviews and general professional discussions of Ongaro's arguments have been positive indeed, render it quite unnecessary to repeat here in all detail why there was such a need. I will therefore focus, in and for this second edition, on a few supplementary, complementary thoughts, and my placing the book into context, from the first one that might still be interesting given the current situation. I have retained the original text wherever possible and amended it wherever needed.

Edoardo Ongaro's book entered the stage at an auspicious moment for such an enterprise, and with not only impressive but also crucial credentials. His many publications, in more empirical, mainstream PA, paved the way for the scholarly community to more readily accept this work as the product of 'one of us'; the very fact that he has served for six-years and the maximum allowed length of the two full terms as the President of the European Group of Public Administration (EGPA), which today is not only the leading learned PA society in Europe, but also one of the, if not arguably the, first such organ- 
isation globally, gave it considerable weight. Having edited a very comprehensive Handbook of Public Administration and Management in Europe (with Sandra van Thiel), he has one of the best perspectives on what is going on in European PA at the moment, and who does what. Maybe this should not matter in an academic context, but of course it does - inevitably, who says something and to whom is part of what is being said, often as crucially so and sometimes more than the plain text itself.

The book is an introduction and a beginning, as the author keeps underlining - and wisely so, not out of false modesty, but because this is the appropriate frame, even in its now substantially amended and developed format, the result of the discourse about and with the first edition. But Philosophy and PA is a huge field, not only because of the contents itself, but also due to the many traditions of Philosophy, which can and does lead to serious infighting - many Continental philosophers would claim that Analytical philosophers are no philosophers at all, and vice versa even more so. Ongaro is able to bridge that gap almost effortlessly, and he allows adherents of all traditions to have a say and an impact. Schooled in the Continental tradition, he now works in a scholarly environment that is part of the other dominant tradition (the Italian higher education institution where he grew up scientifically is also very friendly to Anglo-American thought). His versatility and erudition, unusual for a 21st-century PA scholar, in many languages, including the ancient ones, make such an approach possible.

By taking a pars pro toto approach, Ongaro can classically focus on the long lines, the broad brushstrokes and the long run - but without sacrificing details by also presenting specific thinkers close up. Since he is very explicit about it, a general synthesis - to which we however now come closer - is not lacking, but its absence is part of the story, and the result should be palatable to many. The effect is that it becomes obvious where the lacunae are - both in what this book does not cover and what contemporary scholarship into Philosophy and PA is lacking. There is quantitatively not that much of this, but there is some rather good work, such as Norma Riccucci's and Jos Raadschelders's, which Ongaro extensively takes up - but he goes beyond them in scope, as regards both types and roles of Philosophy in and of PA. This is why this book is at the same time an introductory text for students and a research programme for scholars.

And this is really important - the discipline of PA, which is often without foundation today, needs to assert itself for its own and society's sake, but how to do so without an introductory textbook - which we now have. How many students will graduate with a Master's degree in PA without ever having seriously considered what Aristotle and Hegel have to say about public service? (How many will not even have read Max Weber's short passage on what really constitutes Weberianism in Wirtschaft und Gesellschaft (1922)?) 
Prima facie, this seems like a very European perspective, as compared to the apparently so polytechnical, purely quantitative, mistaking-evidence-as-proof American PA. Of course anything on Philosophy and PA will be European before, say, the 1690s, that is, before the earliest beginnings of any PA thought in the Massachusetts Bay Colony, which was seminally independent from England and thus from Europe. But in fact, as ever so often, this is not the case - while some of the more doctrinaire American journals (including top-ranked ones) will not allow scholarly discussions about Philosophy and PA, it is actually in the American special-interest journals, conferences, working groups and panels where one finds more, if still very little, about the topic, rather than in Old (let alone New!) Europe. So far, virtually all attempts to discuss, in a structured way, Philosophy and PA in Europe have failed. It may be worth considering why, but the fact remains, for the moment at least - although the discussion about Ongaro's book has surely pushed this debate forward in a very constructive way.

In the last paragraph, I said that 'of course, anything on Philosophy and PA before, say, the 1690s will inevitably be European'. This remark is as stupid as it is blind, of course - unless one takes the position that there is one global way of doing PA, that PA is not contextual, and that indeed what is now global PA is without alternative, like engineering or plumbing. This view, which would be considered massively offensive and indeed absurd in many other social science disciplines, still holds sway in PA, and much of consultancy and advice by international organisations to non-Western countries is based on it. But if PA is the implementation of public policy, there must be different ways that all are legitimate - as Aristotle points out in Politics. Global PA = Good $\mathrm{PA}=$ Western PA $=$ Modern PA is, put this way, as bizarre as it is autistic, but the fact is that the alternative way of thinking, that is, recognising that there is such a thing as Non-Western PA (NWPA), is only slowly (re-)surfacing and entering the mainstream PA discourse.

The current book is largely global-Western- but it is consciously so. If consciously done, this is fully legitimate; what is intellectually and ethically terrible, and really not up to scratch for the 21 st century anymore, are works on global PA (or political science, political philosophy, etc.) that are really not global but Western - carrying the White Man's Burden into the new millennium, as it were. But there are no areas left in the world, including the carrier countries of NWPA, which are not 'contaminated' by global-Western PA, which has a very wide, internally contradictory scope anyway (e.g. the anti-state destructionism of NPM versus state-affirming, citizen-focused approaches such as the Neo-Weberian State). Therefore, what underpins global-Western PA is also interesting for NWPA students, and so is this book.

It is here where an addition to and enlargement of the current book might be possible as further steps or volumes. Carefully considering NWPA alternatives 
to the global-Western mainstream has the dual effect of both qualifying and illuminating the latter, making it possible to have a more thorough and more relevant approach to global-Western PA, potentially enabling scholars and practitioners to reposition themselves regarding more appropriate advice and reform. Alas, however, there is very little left as regards currently working, successful forms of NWPA. I would argue that much of the sorry state of PA reform in some non-Western countries is related to this - countries were not allowed to develop their own strengths based on their own traditions, but were told to adopt Western formats, or else (that is, otherwise they would not receive vital funding). But on the level of Philosophy and PA as treated in this book, there actually is a rich, multifaceted, and indeed exciting fundus of NWPA, some in dialogue with Western Philosophy, some quite independent, and both highly relevant.

Just to mention the two perhaps most important NWPA traditions still alive today, that is, those that form genuine challenges to the universalism of the global-Western approach. The first that comes to mind is the Islamic one. This is the main NWPA tradition bordering, and thus challenging, the West, and one that is often perceived, once again, as based on a threatening ideology. It calls out the non-connectedness of religion and PA as a choice (and a wrong one), not something 'given', and it is something the West might have to react to beyond facilely insisting that it should not be so. Much of Islamic state thought, however, has developed in close conjunction with the Greek philosophers, and institutional Islamic $P A$ is usually 'moderate'. In PA itself, the non-delegatability of responsibility that is prominent, for example in the Nizam-ul-Mulk, or the highly sophisticated and philosophically grounded Ottoman PA with its insistence that - yes - the welfare of many is worth the sacrifice of the few; with its legacy of 'creative low-level discrimination' to preserve social peace; with its emphasis on good-enough governance (better much less taxes received than levied than no taxes at all), arguably derived from Islam's rapid expansion; and with a civil service that in many ways was 'super-Weberian', may serve as illustrations.

But it surely is Confucian PA that is the main philosophical challenge, the intellectual 'other' to the Western paradigm, not least because it was earlier and because it did and does work so well. The fact that it is problematic for some to call it 'Confucian' rather than 'Classical Chinese' PA already indicates some pitfalls here because we have Confucian PA not only in Mainland China but also in Hong Kong, Taiwan, South Korea, Vietnam and Singapore; historically also - and quite philosophically grounded - in pre-Meiji, Edo Japan. The idea of a state that is an extension of, rather than a juxtaposition to, the family; the unquestioned supremacy of the bureaucracy even in fine arts and culture; dealing with human flaws such as nepotism and other forms of corruption institutionally rather than by demanding that the human person changes; 
and the focus on performance, so strongly so that an originally legitimate government can be removed even by force if it does not deliver, are aspects that underline both otherness and parallelism. And while Neo-Confucian philosophy of PA (Neo-Confucianism was the state ideology of Imperial China from the 800s until its demise) is independent from Western thought, New Confucian Philosophy is not, but it is also quite distant from PA - not surprising for a philosophical direction that emerged precisely as a reaction to the fall of a state and its management in the first years of the 20th century.

I hasten to say that these traditions are, by and large, not much taught in their carrier countries today either, at least not in PA - the top PA schools in, say, Turkey, China and so on are only gradually adding their own traditions to their curricula, if at all, and if they include any Philosophy as connected to PA, in general, it is global-Western. NWPA is still an uphill-battle approach even in the non-Western countries, but the philosophical enrichment and the potential as described supra remain, for all sides, and it appears that this at least - to mix metaphors - is a train that is going into the right direction.

Speaking about performance, Geert Bouckaert has occasionally differentiated between two aspects of good PA: Equity and Performance. This simple dichotomy has always struck me as heuristically the most helpful one for conceptualising what good PA actually is. It is already a great advance if, in the context of NWPA for instance, we recognise that top marks in the two categories do not automatically go together (they often do, but it is crucial to realise that 'often' is very different from 'always'). The shallowness of the current PA discourse is perhaps best indicated by the fact that we have no theory, no texts, no classes, no discussion of intentionally bad PA in the sense that either universalist or even local norms are consciously broken - and/or delivery is not done! - in order, for example, to keep a regime in power that is mostly interested in just that, for its own selfish reasons. These are courses of action that typically are enmeshed with self-justifications, of course: cynical exploitative tyrannies self-asserting themselves as such are rare. PA, as we saw, is also derivative to a considerable extent - it implements public policies - and the question is whether, in the face of a given government with exploitative attributes, it is up to PA to say whether that regime should be successfully administered, or rather subverted. The independence of a classical Weberian PA vis-à-vis the government, often seen as a disadvantage, turns into an advantage once a regime considered 'bad' comes along - just as NPM, as 'reactionary modernism', is not coincidentally often so appreciated by authoritarian regimes. But how can we even hope to address such basic issues of PA without recourse to Philosophy?

In this context the derivativeness of PA has a theoretically positive side as well. In Philosophy as a scholarly discipline, as in the Humanities in general and in some of the less-applied social sciences, there is a 'wussiness', 
over-conceptualisation and scholastic production of ethical-theoretical quagmires that make it much more complicated than it has to be to have a meaningful discourse. This, in PA, is not the case - it errs on the other side. For instance, NWPA, to the extent that it exists, has, almost elegantly, bypassed the self-serving fashion of the 'Orientalism' discourse (not the original question as raised, but the exclusivity-mongering use of it by tertiary adherents of the concept for their own interest). This means that in several respects, the PA discourse is, or can be, better than the one in contemporary Philosophy itself less introverted and more fruitful.

Along the same lines, the necessary connection that PA as a scholarly discipline has to practice, a feature that is certainly more pronounced than for many of the other social sciences, is not non-philosophical, but quite the opposite; it is potentially a pre-condition for good Philosophy, as not only Aristotle and Kant, but also Plato and Hegel emphasised again and again - if it is not true in practice, the corresponding theory must be abandoned as well. The inherent, necessary practicality of PA has been questioned most recently by approaches prescribing more modelling, more 'theory-driven', open- and (apparently) big-data- or even AI-based, economics-imitating approaches that would like to see, also in PA, less relevance and more rigour (which, as Albert Einstein said in his 1921 Prussian Academy of Science lecture, are indeed enemies of each other), but at the core of PA lies a theory-practice balance and intimate connection, as long as the theory is and can indeed be connected to practice.

Beyond this, and as a final thought, the change of the way of life, indeed of the human person and of how they identify and conceive of themselves, through the Information and Communications Technologies (ICT) revolution is the main issue for PA in our time. It is also a 'fashion' and a hype - and appropriately so; 'believe the hype' - to which funded science and higher education are always extremely sensitive. With its technical propensity, ICT marginalises different approaches to PA even more - but in fact, ICT-based PA in its current stage needs Philosophy, if anything, more, not less. The crucial changes and shifts ICT creates are best addressed outside of e-Governance itself (which is often e-PA), which cannot - and usually does not even want to - pull itself out of the mire of Philosophy by its own hair. In fact, e-Governance is usually even more removed from Philosophy than PA, assuming both a millennial, indeed crusading rhetoric and a set of highly emotional value assumptions that are so internally inconsistent that they are only bearable if cognitive dissonance becomes a principle - privacy, openness, tolerance, safety, self-determinedness, control, uniformity, participation, agency, and so on, do collide, and it is difficult to see how one could balance them or at least sort them out without Philosophy.

Altogether, reflection on PA on a much wider and deeper level than that of the unquestioned assumptions remains both more necessary and more urgent 
today than it has been for a while. We live in an administered world; the reality humans inhabit is to a considerable extent an administered one. To be aware of its foundations is crucial in a time when what we thought were the foundations of our life together all of a sudden break away, both in a technical sense and in a philosophical one, and a technical approach simply is insufficient for coping with, let alone for managing or even for ordering, reality for the polis in the times to come. I am, once again, very glad that Edoardo Ongaro's book has already so impressively contributed to this, and I am certain the success of the first edition of this book will be replicated by its translations addressing new and different audiences, and even further increased by this second edition. 